\title{
Theorizing the relationality of skilled migrants' transnational mobilities
}

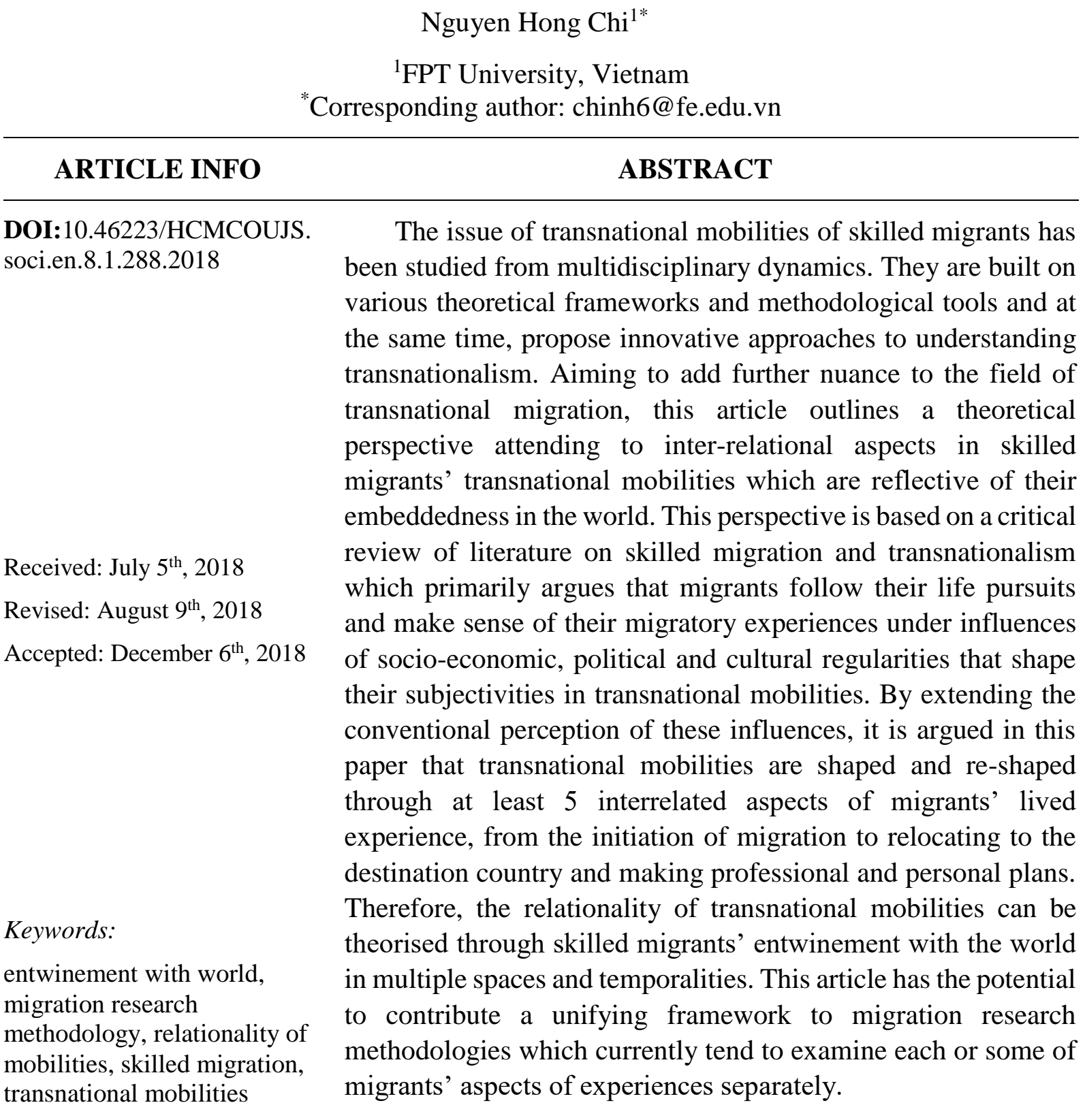

\section{Introduction}

Research on migration often points out that transnational mobilities of skilled migrants are situated within global and national discourses of brain flows for competitive advantage. Migrants' experiences are said to be influenced by their multiple pasts, presents and futures, which exceed the calculative rationality of migrants that policy-makers often dictate. Transnational mobilities are negotiated under confluences of multiple forces that shape migrants' moving decisions and residency outcomes. This requires researchers to design and 
apply a sound theoretical framework that attends to interrelated influences of migrants' engagement with the world, from personal circumstances to interactions with other people and objects beyond the individual level.

This theoretical and methodological issue has been successfully addressed and approached in previous studies which are mentioned in this article. Some research examines transnational mobilities in relation to migrants' responses to global and national regimes of mobilities. Other studies investigate how migrants make sense of their mobilities through their engagement with families, communities and government policies. While acknowledging the influences of these narratives, the author notices that many of these studies examine one or some of the aspects separately. Thus, they neglect the fact that migrants' beings unfold in expected and unexpected ways that are influenced by their embodied subjectivities, which are formed within their holistic involvement in the world. Instead, this paper argues that skilled migrants' transnational mobilities are embodied in their interactions with others and things at multiple related scales. As such, transnational mobilities can be theorised through migrants' experiences of interrelated aspects of their lives. These interrelations include influences from their encounters with families, communities and fellow professionals, as well as intangible and tangible things such as the availability of academic programs and skilled immigration policies.

This paper proposes a theoretical framework that unifies various aspects of the negotiation of transnational mobilities by examining migrants' engagement with the world in interrelated scales and domains. By borrowing a phenomenological term suggested by Dall'Alba's (2009, pp. 35-37) research on higher education, this paper refers to this interrelatedness to "migrants' entwinement with the world". As a theoretical perspective, this framework allows us to explore the complexities of migrants' decisions, aspirations and formation of hybrid selves, as well as sense-making of belonging. As a methodological approach, this framework enables us to follow specific steps in broadening understandings of spatial and temporal linkages in which migrants make choices and decisions for their mobilities.

This framework consists of 5 aspects that are unpacked in the following sections. The paper first outlines migrants' interactions with other people which are simultaneously related to their uses of things. Their interactions with others and things are manifest through their encounter with socio-political and cultural regularities. The next section contends that constraints and possibilities can arise from migrants' embeddedness in these norms. Finally, it points out that the ways they make sense of mobilities are grounded in the interrelation of spatiality and temporality. The paper reviews extant research on skilled, two-step migration and other types of migration.

\section{Interacting with others at multiple scales and domains}

Skilled migrants live in the world which they share with other people at communal, professional and familial levels, as well as at broader socio-political, economic, educational and cultural levels. In involvement in the world, their constant interactions with others at various scales influence their transnational mobilities in several ways.

For example, some skilled migrants are sent to work in other countries by transnational corporations that run offshore branches and choose to reside at a later stage (Beaverstock, 2005). In some sense, their mobilities are formed by not only their own desires but also the decisions of managers of the companies they are working for. Regarding personal expectations, E. L.-E. Ho's (2011) research showed that skilled migrants self-initiate journeys to global cities 
like New York or London to earn credibility for career building aspirations. Although there seems to be little influence from other people on their decision to move, these migrants' mobilities are indirectly affected by their own and public imaginations about entrepreneurial lifestyles that people in these mega-cities follow, and that can enhance their living skills for professional advancement. Under influences from those they know or may not know, some migrants are reported to relocate to another country for employment by utilizing family ties (Nagel, 2005), or follow academic career opportunities provided by the increasing growth of research universities (Kim, 2010). In addition, in the current global race for talent, skilled migrants are depicted as active agents looking for jobs which are offered by skill attraction policies. Attractive bonuses included in these policies help facilitate their migration to "airconditioned nations" (George, 2000, p. 18) with state-of-the-art infrastructures, architectures and luxurious living conditions. Similarly, under the effects of Vietnam's recent economic transformations, expatriates are motivated to return home by material attractions described in the government's diaspora strategies (Dang, 2003). These studies have collectively implied the influences of socio-economic changes, skilled (im) migration and diaspora strategies and transnational connections on skilled migrants' experiences of belonging.

In and through connections with family members, migrants' mobilities are either limited or initiated by domestic roles and responsibilities. In his research on Indian skilled migration, Biao $(2005,2007)$ contended that the costs for some male skilled migrants' education-related migration are compensated by a possibility to bargain the value of dowries with bridal families who can fund their study sojourns in Western countries. Not only can this ensure the subsequent migration of the brides, but it also brings a social status marker to the bridal families at home. An entirely different scenario can be seen among female skilled migrants who are portrayed as dependent spouses, or "secondary" and "tied" migrants whose employment prospects and professional practices are limited by domestic duties (Yeoh \& Willis, 2005a, p. 211). From this, it can be referred that skilled migrants can either take advantage of possibilities and avoid constraints for their migration through their negotiations of cultural practices and gender relations with other people or must confront pressures resulting from their connections with others. This point is further elaborated in the remainder of this article.

It should be noted here that both male and female migrants are embodied subjects with affections and emotions, a less studied area. Conradson and Mckay (2007) noted that emotions are always inherent in mobilities, as migrants share the ways they live their lives with other people in many circumstances, no matter whether these constellations are geographically proximate or distant, and "located in the present or past" (p. 167). Some research on migrants' transnational relationships has shown that migrants experience various feelings that affect their decisions to migrate and reside. These "felt-dimensions" (Conradson \& Mckay, 2007, p. 167) may include filial piety and commitment towards families, friends and communities, or guilt when they cannot fulfill communal or familial obligations. These emotions are affected by their contact and interactions with other people. For instance, Robertson's (2011a) research on international students awaiting PR (permanent residency) outcomes in Australia posited that education migrants encounter a mix of negative and positive feelings such as anxiety, disappointment, happiness and hopelessness that come from their interactions with their families. To prove her argument about prospective student-turned-migrants' precariousness, Robertson (2011a) told a story about a would-be student-migrant who failed to pay an unexpected tax debt because of lack of clear advice on the change of her tax status. This future migrant was unable to fly back home to attend a family funeral. This made her feel extremely 
guilty, sad and skeptical about her residency prospects. In other words, emotions show migrants' very existence, allowing migration researchers to understand costs for mobilities through the relations between migrants and others in the surrounding world.

To explore the influences of emotionality on migration, researchers should pay attention to migrants' relational engagement with the world, as this produces and affects transnational subjectivities. We must probe into migrants' experiences of their engagement with other people in "multiple (and not just social) timespaces of movement" (Shubin, 2015, p. 351). In an engagement with the world, migrants are known to confront challenges, encounter precariousness and identify opportunities. Exploring various ways migrants experience (contradictory) emotions can help researchers partly reveal the complexities of mobilities.

\section{Using tangible and intangible things}

The relationality of transnational mobilities can also be explored through migrants' interactions with things that shape their inter-subjectification, as well as create constraints and enablers to migration trajectories. Things can be divided into tangible objects and intangible relationships including networks, memories, language proficiency, citizenship or skills. The latter are often implicitly manifest in material artifacts which may include photos, letters, gifts, passports and certificates.

For example, some studies (e.g., Baas, 2006; Dustmann \& Fabbri, 2003; Robertson, 2008) focused on migrants' uses of tools such as educational qualifications, English language certificates and skills, telecommunication devices, certifications of working experiences and ethnic networks. Dustmann and Fabbri's (2003) large-scale surveys in the UK explored the effects of English language proficiency on earning and employment capabilities among nonwhite immigrants. These two researchers concluded that language proficiency produces a positive impact on employment and earning capacities of skilled immigrants, while low skilled immigrants who are lack of English fluency often face earning deficiency. While limited English language proficiency is said to pose a constraint to migrants' integration into labour markets, little is known about how the uses of native languages can help them look for jobs in ethnic industries. The same issue can be questioned in other studies which examine how migrants use email and the Internet to maintain transnational lives (Robertson, 2008; Vertovec, 2004). Despite the researchers' specific foci in their research processes, most of these studies investigate migrants' relations with things in isolation. As such, they seem to be unable to portray the complexities of how the uses of things can be related to other things and people.

In contrast, some other studies have implicitly considered migrants' uses of things in relation to other things and people in various domains. By looking into how professional Indian migrants in Australia constitute transnational lives, Singh, Robertson, and Cabraal (2012) argued that while remittances and gifts are valued as a commendable attitude of caring, these things are perceived to gain less weight than migrants' physical care. In other words, things are expected to be used in combination with the ways migrants reproduce family relationships and fulfill familial obligations. Similarly, Biao's $(2005,2007)$ work showed that some skilled migrants initiate their mobilities by using benefits emerging from their romantic relationship and marriage bonding in host countries either by choice or cultural practices. Biao (2007) concurrently postulated that migrants' uses of these relationships are enacted in close relation to the ways they retrieve possibilities and confront ethnic features in castes that value racial bonds. The idea of things related to people is also proven in a strand of research on migrants' 
uses of social media. Media devices are known to generate impacts on how migrants sustain transnational practices with other people (Robertson, 2008; Vertovec, 2004). For instance, cheap international phone calls are used as "a kind of social glue" (Vertovec, 2004, p. 219) that maintains migrants' ties with their relatives in home countries, enabling them to eliminate propinquity in the intersecting personal and social aspects of their lives.

Purposes of skilled migrants' uses of things are also expressed in their participation in broader social, educational and political contexts in which they may encounter other people with whom they may or may not be acquainted. In her research on education-related migrants in Australia, Robertson (2011a) stated that many would-be migrants consider PR as a "holy grail" (p. 107). They accept to pay expensive fees for PR services provided by licensed and unlicensed migration agents and use social networks to enable the subsequent application for residency after education. Some choose to follow academic programs that are demanded in the occupation list and provided by institutions which are notoriously associated with "PR factories" (Baas, 2006, p. 12). Other students are reported to utilize fraud marriages and documents or even cheat in exams to fulfill degree requirements so that they can apply for PR later. Their strategic uses of these tools, which are deployed in relation to other things and people, make governments and the media portray them as "backdoor migrants" (Robertson, 2011 b, p. 2196) who challenge the state in selecting the most appropriate and necessary skills for the labour market.

In addition, citizenship is used as a tool to inter-subjectify migrants' multiple forms of belonging. While migrants aspire to use citizenship (which is shown in their passports) to acquire legal residency status, the meanings of citizenship are usually diverse. For example, Nagel (2005) revealed that Arab managerial migrants working for transnational corporations in London maintain ethnic links to their communities in London as a cultural tie. However, because local people construe them as foreigners and associate them with terrorism, they use their British nationality to participate in Arab political organizations in the UK to contest the public bias towards Arab foreignness. This means that they use their citizenship as equipment to secure political patronage and social positioning in the receiving country. This also means that migrants' negotiation of belonging may become the same as or opposite to what the state dictates citizenship to be. The notion of "home" as implicitly indicated in passports is constructed by migrants' dealings with both external and internal relations when they are located in a place (Conradson \& Mckay, 2007). Governments often expect that becoming a citizen represents a commitment to the nation and allows migrants to fully participate in all aspects of life. However, migrants may not feel entirely belonging to host societies. Some choose to apply for dual citizenship, while others join transnational networks and organizations for cultural and religious practices.

Generally, migrants do not use one thing in isolation. For example, international students use their educational qualifications together with certificates of English language proficiency to apply for PR. These qualifications can be submitted in combination with their dependent spouses' educational qualifications and birth certificates so that their PR applications can be given bonus points. In this sense, migrants' uses of things in relation to other things and people show the embodiment of their mobilities in seeking authentic belonging. 


\section{Engaging in social regularities}

We are known to always follow sets of family and community routines, social practices and state regulations that are often called public norms. Similarly, skilled migrants' interactions with others and things are embedded in how they practice these social norms, which convey meanings to their transnational mobilities (Lee \& LiPuma, 2002, p. 192). The ways migrants follow or break with social practices and norms are embedded in how they make sense of their interactions with others and things.

For example, Biao $(2005,2007)$ noted that communal practices of marriage and social perception of migration for social status significantly affect skilled migrants' decisions to migrate and relocate. In the same vein, transnational kinship practices influence the ways migrants fulfill familial obligations and achieve migration aspirations. In addition, in a study of Vietnamese married migrants in Singapore, Yeoh, Leng, Dung, and Yi'en (2013) were concerned with the meanings of cultural practices and family duties that are present in remittances and gifts. These migrants express diverse emotions in their attempts to improve economic conditions in their natal families by trying to send remittances to become dutiful daughters, while they are confronting domestic pressures in their martial families at the same time. They face challenges posed by following the cultural practice of filial piety in Vietnam and patriarchy in Singapore that affect their experience of mobilities and belonging.

By examining negotiations of mobilities in a broader socio-political context, some studies (e.g., Favell, 2003; E. Ho \& Bedford, 2008) acknowledge the influences of migrants' dealings with social regularities on their trajectories and relocation. Favell (2003) noticed that political norms in some receiving countries such as France and the UK mandate migrants' integration, whereas their participation in transnational Muslim networks allows resistance against the state integration requirements. Transnational mobilities are also re-constructed by the ways migrants choose to follow or break with social norms, as evidenced in E. Ho and Bedford's (2008) study. Parents of some Hong Kong students, who pursue secondary and tertiary education in New Zealand and later apply for PR, choose to move back and forth between Hong Kong and New Zealand as astronaut parents to take care of their children. Their mobilities may be constrained by the regime of PR visas which, however, leads to the possibility for frequent temporary mobilities that are connected to their children's decisions to apply for PR.

It is worth noting that some studies which insist on the duality between agency and structure usually describe social regularities as located in stasis, which is affected by migrants' mobilities. However, this conventional perception is challenged in several regards. Firstly, Nguyen (2015) asserted that social structures can only create significant impacts on mobilities if the number of migrants and their participation in transnational networks are large enough to produce changes to social mechanisms. Migrants' mobilities are shaped by the ways they follow social regimes. Secondly, this binary considers migrants as being contained within social structures that are then viewed as immobile objects. This perception limits the analysis of the interrelationship between fixity and mobility (Glick-Schiller \& Salazar, 2013, p. 183). In contrast, it has been argued so far in this paper that because of being always embedded in the world with social regularities, migrants negotiate decisions to migrate and relocation strategies through the ways they follow or break with social norms and political ideologies in both home and host societies, all of which potentially influence their mobilities. 


\section{Dealing with constraints and possibilities}

Previous studies have shown that migrants' embeddedness in the world creates constraints, and when they deal with constraints, possibilities may open up, or they may have to face further constraints. The following examples are taken to support this argument.

Being aware that skilled migration policies would be revised in the mid-2000s, some international students in Australia quickly undertook academic programs that were listed as occupations in high demand and rushed to graduate before the immigration policy changes became effective (Baas, 2006). Some Master's level students who were predictably unable to meet the PR requirement of a two-year period of residence in Australia decided to immediately transfer to universities which offered two-year programs. Some universities were believed to provide courses in which students' attendance seemed to be "simply up for sale" (Baas, 2007, p. 50, p. 58). This example shows that would-be migrants' strategies for dealing with constraints posed from interrelated educational and political structures emerge from their interactions with people in educational institutions (friends, administrators and lecturers), and things (academic courses and university degrees).

Another example relating to skilled immigration in Australia can well illustrate this point. As observed in Bass's (2014) study, some Indian skilled migrants who were working as taxi drivers and were victims of violent attacks in Australia began to gain their voices by participating in street rallies with Indian students in Melbourne to challenge racial discrimination. These public demonstrations allowed them to partly reshape the public perception of Indian migrants as peripheral residents. Consequently, the Australian Government seemed to, from 2009, respond to these reactions by strengthening PR visa requirements with regards to skills and employer sponsorship to minimize risks of skill waste in the labour market (Phillips \& Spinks, 2012, p. 4).

Migrants also face constraints arising from their everyday interactions with colleagues, dealing with family circumstances, as well as following cultural and socio-political norms. For example, in C. Ho's (2006) research, many female migrants from China are found to quit their jobs in Australia or choose to work part-time to achieve mothering roles, whereas male migrants undergo little change in their household duties. These female migrants receive limited support for their family responsibilities in Australia, because they are supposed to comply with cultural imposition on the "appropriate role for a woman" in "tak[ing] care of the children and the house" (p. 505). Their limited access to earnings in Australia extends gender inequalities within the migration. This example allows us to understand that difficulties posed by social and cultural practices are often encountered in close relation to migrants' embeddedness in work and familial aspects.

Confronting constraints may lead to possibilities. Biao $(2005,2007)$ showcased an opening of possibilities from constraints in employment that some IT Indian female migrants encounter. These migrants are often sexually harassed while they are waiting "on the bench" for "body shops" to farm them out for overseas projects (Biao, 2005, p. 364). However, these women are eventually able to find out possibilities for migrating to New Zealand through another body shop, their communication with other female migrants in New Zealand, assistance from migration services. Similarly, Nagel's (2005) research focused on mixed tensions that a 
skilled Egyptian female migrant endured after she had given up her job in the UK and divorced. However, her new marriage and job as a social worker for Arabic-speaking patients in London enabled her to improve her self-esteem and form a new identity. Further, by exploring how professional Chinese-Malaysian migrants in Singapore maintain family relationships and care, Lam, Yeoh, and Law (2002) found that many male migrants arrange their wives and children to live with their natal parents in Malaysia, and try to communicate with them through frequent phone calls. Other migrants familiarize themselves with the feeling of being "incomplete" parents (p. 130), because they believe that their children will receive a good education and mother care in Malaysia, while their migration to Singapore can earn a stable income for their families. It can be inferred that when these male migrants deal with the constraint occurring from geographical distances, they can realize the potential of economic improvement from employment in Singapore and their children's educational security in Malaysia.

In short, while some difficulties such as the death of a relative cannot be coped with, others can be overcome. They are said to occur before migration and during relocation. Confronting constraints through interactions with the world allows migrants to realise an opening of possibilities that affects their mobilities. Cresswell (2013) captured the opening of possibilities as "heat", a "by-product" (p. 5) of friction, which can re-form the meanings of mobilities.

\section{Experiencing spatiality and temporality}

Spatiality and temporality have appeared as an emerging issue in current migration research. In general, space is referred to both physical and transnational places where migrants negotiate social reproduction, and time is considered as influences of migrants' pasts and presents on their mobilities. This section primarily supports this viewpoint and adds nuance in that space and time are interrelated, and the interrelation between these two aspects produces significant impacts on the meanings of mobilities.

Migrants do not simply experience geographical spaces and physical movements across space, nor are they merely contained in space. Instead, space is experienced through its entwinement with the world. This point has been mentioned in some earlier research reports. For example, in a study on Vietnamese diasporas in Australia in the late 1990s, Thomas (1999) found that these migrants use gifts to compensate their absence from home, relieve their nostalgia, and offer their relatives a sense of foreignness from Australia. However, their relatives often feel disappointed, because they want to receive money instead of consumption products. The contradictory feelings between gift giving and receiving demonstrate that these migrants experience spatiality in a close link to their past filled with memories about their relatives and hardship after the Vietnam War. They feel dislocated when knowing that their relatives are not happy to receive the gifts and later sell them for money. The space the Vietnamese diasporas experience encompasses their experiences in interacting with their relatives, material objects, memories and emotions. Not only does space manifest itself in geographical distances, but it also is negotiated through migrants' involvement in the world in multiple linkages of spaces and times. Space exists within migrants' intersubjective-making of places with others and things (Shubin, 2015, pp. 352-353). 
Migrants' experience in space allows them to seek their authentic selves by making sense of multiple experiences from their involvement in the world, making transnational mobilities a continual and fluid process. This point can be elaborated in Yeoh and Willis's (1999) study of Singaporean economic migrants in China. These migrants' decisions to migrate are made under influences of place-based cultural norms of marriage and marriage plans, which enhance and constrain their decisions to migrate and plans for professional and social mobility. When later looking at the mobilities of Singaporean and British business migrants in China, Yeoh and Willis (2005b) similarly highlighted some challenges and opportunities in cultural adaptation that these migrants experience. While both groups follow cultural practices in China, the meanings of their actions are different. Specifically, by sharing a similar ethnic background, Singaporean migrants find cultural differences attractive and decide to follow the same cultural practices in China. In contrast, British migrants want to minimize cultural familiarity that already exists in western countries by challenging themselves in dealing with difficulties in the new professional environment with different cultural practices.

As mentioned above, previous studies have shown that space is interrelated to time in some ways. This understanding contrasts with the conventional perception of temporality as a "staged chronology of migration" (Shubin, 2015, p. 350) that goes linearly from migrants' decision to migrate to relocation and completion of migration after arrival in host countries (Cwerner, 2001). By critiquing the notion of time as linearity, Robertson (2014) noted that time tends to be viewed as separate from space when it turns to be "subordinate" to space (p. 1917). In this vein, time and space become objective domains in which migrants are reported to respond to separate events (Nguyen, 2015, p. 49). Some studies that take on board transnationalism perspectives conceptualize temporality as lived time that manifests itself in migrants' experiences (e.g., Basch, Glick-Schiller, \& Blanc-Szanton, 1996; Glick-Schiller \& Salazar, 2013; Nagel, 2009). In general, it is argued that migration does not happen in a single space or time but is "the geographical stretching of social relations" (Massey, 1993, p. 60) within a duration of time, which shapes and reconstructs migrants' belonging. It is noticed that these studies place a strong focus on the issue of belonging to place that migrants negotiate during their relocation and making professional and personal plans. They explore how place attachment and mobility are experienced as contradictory and/or complementary forces. This approach leads to a question of how migrants experience time through their embeddedness in place. For example, by viewing migrants' experiences as being influenced by confluences of their embeddedness in place, Nguyen (2015, p. 50) argued that migrants always experience space in relation to time. Supporting the same view by other researchers (e.g., Robertson, 2011a; Yeoh et al., 2013), Nguyen (2015) affirmed that space and time are encountered through intersecting influences of migrants' duty, responsibility, and desire which are shaped by their past experiences and future projection. Simply put, this is the effect of migrants' entwinement with the world. Their dwelling in the world with others and things across space and time makes transnational mobilities fluid and complex, rather than fixed and linear.

When viewing time and space as interrelated aspects, Cresswell (2006) stated that mobilities are constituted by the "spatialization of time and temporalization of space" (p. 4). In line with this perception, mobilities are not a "function" of time and space, but migrants" experiences of their encounters with the world to negotiate mobilities can produce time and 
space. This is congruent with what has been discussed so far. It is collectively argued that mobilities do not only include geographical movements from one place to another, but also strategies and tactics that migrants use for and in their mobilities. In directing themselves and being directed towards a place, migrants may successfully arrive at a destination as devised in their initial itinerary. They may also re-direct routes and add extra meanings to their journeys, or eventually settle in another destination as they find other opportunities open up during their sojourns. As such, transnational mobilities are negotiated through migrants' attempts to stretch social relationships across space from the beginning of migration to current relocation and future prospects. In other words, time is experienced in relation to how migrants experience space. Taken together, time and space are encountered as happenings and incompleteness of migrants' lives. Migrants always project themselves into the future by making sense of their experiences of living across the past and present in various social domains and geographical spaces.

\section{Conclusion}

This article has argued that transnational mobilities are negotiated in and through interrelated aspects of migrants' lives. It provides a timely response to calls for theoretical and methodological approaches which attend to the geographies of migrants' everyday lives that influence the negotiation of transnational mobilities (e.g., Conradson \& Mckay, 2007; Cresswell, 2006; Shubin, 2015; Yeoh \& Willis, 2005b). Migrants' engagement in the world is often complex because of their diverse interactions with others and things in multiple spatial and temporal linkages. Exploring this complex relationality requires researchers to adopt a theoretical framework that allows reasonable methodological approaches to be applied.

While previous studies have mentioned this relationality, they tend to examine each of the aspects separately from the other. This limits a holistic view of migration as an on-going process. By reviewing related literature in transnationalism and skilled migration, this paper proposes at least 5 interrelated aspects in transnational mobilities that future studies should pay attention to. These include (1) migrants' interactions with others, which are (2) interrelated to their encounter with things, (3) migrants' ways to follow or break with regularities that are embedded in their interactions with others and things, (4) possibilities and constraints that emerge from migrants' encounter with the world, and (5) their experiences of the intertwined spatiality and temporality that results from their embeddedness in the world. This theoretical approach is termed as "migrants' entwinement with the world".

This theoretical perspective offers a unifying framework used to understand transnational mobilities as a wholistic process. It allows us to explore how migrants negotiate transnational mobilities in intersecting social and personal domains, rather than how they deal with policy influences or family circumstances as separate happenings. Accordingly, this perspective enables us to examine how migration processes and outcomes are shaped not only by imaginations of migration before departure, but also by migrants' concrete relocation experiences and plans for the future. Migrants' intersubjectivities of transnational mobilities are formed through their multiple connections to other people, things and events in intersecting spaces and times. This approach to exploring the interrelated aspects of experiences in transnational mobilities helps unpack how migrants mediate the effects of global, national and local processes with personal motivations. 


\section{References}

Baas, M. (2006). Students of migration: Indian overseas students and the question of permanent residency. People and Place, 14(1), 8-23.

Baas, M. (2007). The language of migration: The education industry versus the migration industry. People and Place, 15(2), 49-60.

Baas, M. (2014). Victims or profiteers? Issues of migration, racism and violence among Indian students in Melbourne. Asia Pacific Viewpoint, 55(2), 212-225.

Basch, L., Glick-Schiller, N., \& Blanc-Szanton, C. (1996). Nations unbound: Transnational projects, postcolonial predicaments and de-territorialized nation-states. New York, NY: Gordon and Breach.

Beaverstock, J. V. (2005). Transnational elites in the city: British highly-skilled inter-company transferees in New York City's financial district. Journal of Ethnic and Migration Studies, 31(2), 245-268.

Biao, X. (2005). Gender, dowry and the migration system of Indian information technology professionals. Indian Journal of Gender Studies, 12(2-3), 257-380.

Biao, X. (2007). Global "body shopping”: An Indian labour system in the information technology industry. Princeton, NJ: Princeton University Press.

Conradson, D., \& Mckay, D. (2007). Translocal subjectivities: Mobility, connection, and emotion. Mobilities, 2(2), 167-174.

Cresswell, T. (2006). On the move - Mobility in the modern Western world. New York, NY: Routledge.

Cresswell, T. (2013). Friction. Paper presented at the International Conference on Theorizing Mobilities in/from Asia Conference, Asia Research Institute, National University of Singapore, Singapore.

Cwerner, S. B. (2001). The times of migration. Journal of Ethnic and Migration Studies, 27(1), 7-36.

Dall'Alba, G. (2009). Learning professional ways of being: Ambiguities of becoming. Educational Philosophy and Theory, 41(1), 34-45.

Dang, N. A. (2003). Vietnam: Emergence of return skilled migration. In R. Iredale, F. Guo \& S. Rozario (Eds.), Return migration in the Asia-Pacific (pp.136-168). Northampton, MA: Edward Elgar.

Dustmann, C., \& Fabbri, F. (2003). Language proficiency and labour market performance of immigrants in the UK. The Economic Journal, 113(489), 695-717.

Favell, A. (2003). Games without frontiers? Questioning the transnational social power of migrants in Europe. European Journal of Sociology, 44(3), 397-427.

George, C. (2000). Singapore: The air-conditioned nation - Essays on the politics of comfort and control 1990 - 2000. Singapore: Landmark Books.

Glick-Schiller, N., \& Salazar, N. B. (2013). Regimes of mobility across the globe. Journal of Ethnic and Migration Studies, 39(2), 183-200. 
Ho, C. (2006). Migration as feminization? Chinese women's experiences of work and family in Australia? Ethnic and Migration Studies, 32(3), 497-514.

Ho, E. L.-E. (2011). Identity politics and cultural asymmetries: Singaporean transmigrants "fashioning" cosmopolitanism. Journal of Ethnic and Migration Studies, 37(5), 729-746.

Ho, E., \& Bedford, R. (2008). Asian transnational families in New Zealand: Dynamics and challenges. International Migration, 46(4), 41-62.

Kim, T. (2010). Transnational academic mobility, knowledge, and identity capital. Discourse: Studies in the Cultural Politics of Education, 31(5), 577-591.

Lam, T., Yeoh, B. S. A., \& Law, S. (2002). Sustaining families transnationally: Chinese Malaysians in Singapore. Asian and Pacific Migration Journal, 11(1), 117-143.

Lee, B., \& LiPuma, E. (2002). Cultures of circulation: The imaginations of modernity. Public Culture, 14(1), 191-213.

Massey, D. (1993). Power geometry and a progressive sense of place. In J. Bird, B. Curtis, T. Putnam, G. Robertson \& L. Tickner (Eds.), Mapping the futures: Local cultures, global change (pp. 59-69). New York, NY: Routledge.

Nagel, C. R. (2005). Skilled migration in global cities from “Other” perspectives: British Arabs, identity politics, and local embeddedness. Geoforum, 36(2), 197-210.

Nagel, C. R. (2009). Rethinking geographies of assimilation. The Professional Geographer, 61(3), 400-407.

Nguyen, C. H. (2015). Transnational mobilities of Australia-educated and domiciled professional migrants from Vietnam (Doctoral dissertation, University of Queensland, Brisbane, Australia).

Phillips, J., \& Spinks, H. (2012). Skilled migration: Temporary and permanent flows to Australia. $\quad$ Retrieved March 20, 2018, from http://parlinfo.aph.gov.au/parlInfo/download/library/prspub/1601351/upload_binary/16 0135 1.pdf;fileType=application\%2Fpdf

Robertson, S. K. (2008). Negotiated transnationality: Memberships, mobilities and the studentturned-migrant experience (Doctoral dissertation, RMIT, Melbourne, Australia).

Robertson, S. K. (2011a). Student switchers and the regulation of residency: The interface of the individual and Australia's immigration regime. Population, Space and Place, 17(1), 103-115.

Robertson, S. K. (2011b). Cash cows, backdoor migrants, or activist citizens? International students, citizenship, and rights in Australia. Ethnic and Racial Studies, 34(12), 21922211.

Robertson, S. K. (2014). Time and temporary migration: The case of temporary graduate workers and working holiday makers in Australia. Journal of Ethnic and Migration Studies, 40(12), 1915-1933. doi:10.1080/1369183X.2013.876896

Shubin, S. (2015). Migration timespaces: A Heideggerian approach to understanding the mobile being of Eastern Europeans in Scotland. Transactions of the Institute of British Geographers, 40(3), 350-361. 
Singh, M., Robertson, S., \& Cabraal, A. (2012). Transnational family money: Remittances, gifts and inheritance. Journal of Intercultural Studies, 33(5), 475-492.

Thomas, D. C. (1999). Cultural diversity and work group effectiveness: An experimental study. Journal of Cross-Cultural Psychology, 30(2), 242-263.

Vertovec, S. (2004). Cheap calls: The social glue of migrant transnationalism. Global Networks, $4(2), 219-224$.

Yeoh, B. S. A., \& Willis, K. (1999). "Heart" and "wing", nation and diaspora: Gendered discourses in Singapore's regionalism process. Gender, Place and Culture, 6(4), 355372.

Yeoh, B. S. A., \& Willis, K. (2005a). Singaporeans in China: Transnational women elites and the negotiations of gendered identities. Geoforum, 36(2), 211-222.

Yeoh, B. S. A., \& Willis, K. (2005b). Singaporean and British transmigrants in China and the cultural politics of "contact zones". Journal of Ethnic and Migration Studies, 31(2), 269285.

Yeoh, B. S. A., Leng, C. H., Dung, V. T. K., \& Yi'en, C. (2013). Between two families: The social meaning of remittances for Vietnamese marriage migrants in Singapore. Global Networks, 13(4), 441-458. 